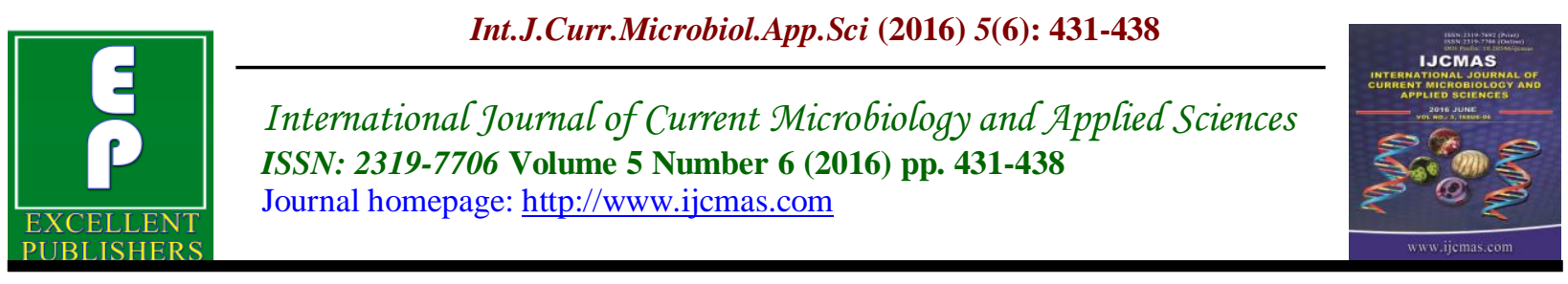

Original Research Article

http://dx.doi.org/10.20546/ijcmas.2016.506.050

\title{
A Study on Bacterial and Fungal Profile of Infections in Patients with SLE
}

\author{
V. Shiney John*, S. Vasanthi and N. Rathnapriya \\ Department of Microbiology, Ponnaiyah Ramajayam Institute of Medical Sciences, \\ Chennai, India \\ *Corresponding author
}

\begin{tabular}{|c|c|}
\hline & A B S T R A C T \\
\hline & chronic autoimmune disorder in which multiple systems of the body are \\
\hline Keywords & affected. Infections are one of the leading causes of morbidity and mortality in SLE \\
\hline SLE, & patients and the percentage of patients who develop infections range from $33 \%$ to \\
\hline $\begin{array}{l}\text { Infections, } \\
\text { Bacterial, }\end{array}$ & $\begin{array}{l}50 \% \text {. Hence the present study was conducted to isolate and identify the various } \\
\text { bacterial and fungal pathogens associated with infections in patients with SLE. } 110\end{array}$ \\
\hline Fungal, & SLE patients with clinically suspected infections were included in this study. \\
\hline $\begin{array}{l}\text { Urinary tract, } \\
\text { E.coli, Candida. }\end{array}$ & $\begin{array}{l}\text { Appropriate samples were collected and processed to isolate bacterial and fungal } \\
\text { pathogens. The pathogens were identified using standard methods and their }\end{array}$ \\
\hline Article Info & ed in $60(54.55 \%)$ patients. Urinary tract was the most common site \\
\hline $\begin{array}{l}\text { Accepted: } \\
20 \text { May } 2016 \\
\text { Available Online: } \\
\text { 10 June } 2016\end{array}$ & $\begin{array}{l}\text { accounting for } 93.24 \% \text { of infections. E.coli was the most common bacteria and } \\
\text { Candida was the common fungus isolated. The most common sites of infection and } \\
\text { isolated pathogens were similar to those in the general population. Since infections } \\
\text { are a major cause of morbidity and mortality in SLE patients, all fevers should be } \\
\text { evaluated to rule out infections. }\end{array}$ \\
\hline
\end{tabular}

\section{Introduction}

Systemic Lupus Erythematosus (SLE) is an autoimmune disorder in which multiple systems are affected. In SLE, there is production of autoantibodies which are directed against nuclear and cytoplasmic constituents of the cell. It is a disease which predominantly affects women in their peak reproductive period and is an important cause of morbidity in that age group of females.

SLE may present with variable symptoms which may range from skin and joint involvement to major organ involvement. Corticosteroids and other immunosuppressants are used for treating disease exacerbations. Disease activity and infection are important causes of morbidity and mortality in patients with SLE. It is suggested that infections may also play a main part in exacerbation of disease activity in SLE.

SLE patients are inherently at risk for developing infections due to various immunological dysfunctions. 
Immunosuppressants which are used in the treatment of SLE further increases the susceptibility to infections. The percentage of SLE patients who develop infections range from $33 \%$ to $50 \%$. Early recognition of infections is important as they may mimic SLE flares leading to a delay in diagnosis or inappropriate increase in doses of immunosuppressants with catastrophic consequences. The published articles on infections in SLE patients from South India are limited. Hence the present study will give an insight into infections in SLE patients.

\section{Materials and Methods}

This cross sectional study was conducted for a period of one year. The study included 110 SLE patients with clinically suspected infections who were admitted or visited the outpatient departments of our hospital during the study period. Specially designed questionnaire was used to collect demographic and clinical information from the patients.

Under strict aseptic precautions samples like urine, sputum, bronchoalveolar lavage, ascitic fluid, cerebrospinal fluid, oral scraping, nail clipping, pus, blood and faeces were collected from the patients and transported immediately to the laboratory and processed.

The samples were initially examined macroscopically and then subjected to direct microscopic examination using wet mount, Gram staining, Ziehl Neelsen technique for acid fast bacilli, 10\% Potassium hydroxide mount and India Ink preparation for CSF samples.

The samples were inoculated on appropriate bacterial and fungal culture media. The bacterial and fungal isolates grown were identified by standard microbiological techniques as recommended by Clinical and Laboratory Standards Institute (CLSI). The Candida isolates were speciated by Gram staining, Germ tube test, colour of colonies on CHROMagar and sugar fermentation reactions.

\section{Results and Discussion}

Out of 110 SLE patients included in the present study 98 were female and 12 were male. There was a female preponderance with a female: male ratio of $8: 1.52 .73 \%$ of the patients were in the age group of 21 to 30 years. The mean age of male and female SLE patients were 24.83 and 25.68 respectively. The average duration of SLE was 37 months (3.08 years)

The frequency of patients with and without infection is shown in Table 1. Among the 110 SLE patients $60 \quad(54.55 \%)$ had infectious episodes, out of which 51 had one episode, 8 had two episodes and one patient had 3 episodes of infections. Out of the 60 patients with infection 53 were female and 7 were male and 3 patients died during the study period due to infections like pneumonia and sepsis.

Figure 1 depicts the distribution of various samples with significant growth. The total number of samples collected from the patients were 150 and out of them 74 showed significant growth. Urinary tract infections (54\%) were common followed by respiratory tract infections (16\%). Bacterial infections were predominant than fungal infections.

Table 2 shows the distribution of isolated organisms from various sites. The most common bacteria isolated was found to be E.coli, followed by Pseudomonas aeruginosa, Klebsiella pneumoniae and 
Staphylococcus aureus. The other less frequently isolated bacterial pathogens were as follows: Staphylococcus epidermidis, Acinetobacter baumannii, Enterococcus faecalis, Proteus mirabilis, Citrobacter freundii, Klebsiella oxytoca and Salmonella typhi.

Figure 2 describes the distribution of various organisms isolated from urinary tract. Out of 84 urine samples processed significant growth was present in 40 samples. E.coli was the predominant Gram negative bacteria isolated from 20 (50\%) samples. Among Gram positive bacteria, Staphylococcus aureus was the common isolate from $4(10 \%)$ patients.

Table 3 depicts the distribution of various organisms from respiratory tract. A total of 23 samples were processed from respiratory tract, out of which 12 samples showed significant growth. Klebsiella pneumoniae was the predominant organism isolated from $8(66.67 \%)$ patients. The distribution of organisms from blood is shown in Table 4. 21 blood samples were processed and significant growth was present in 9 samples. The Gram negative bacteria associated with sepsis were as follows: Klebsiella pneumoniae, Pseudomonas aeruginosa, Salmonella typhi and Acinetobacter baumannii. Staphylococcus aureus was responsible for sepsis in 2 patients and Staphylococcus epidermidis in one patient.

The various organisms isolated from skin and soft tissue are shown in Table 5 and the organisms are as follows: Pseudomonas aeruginosa (4), Staphylococcus aureus (3) and Candida albicans (1). Aspergillus flavus and Pseudomonas aeruginosa one each were isolated from ear infection. Candida albicans was isolated from oral cavity of 2 patients with oral thrush. Pseudomonas aeruginosa was the causative agent of peritonitis in one patient with SLE.
Among the 110 SLE patients included in the study there were 98 female and 12 male. The female: male ratio of SLE patients in the present study was 8:1. Malaviya et al., and Jacobsen, Peterson et al., in their study reported a female to male ratio of $8: 1$. Most of the patients $(52.73 \%)$ in this study were in the reproductive age group of 21 to 30 years. This is in agreement with the study by RenuSaigal et al., in which majority of patients were in the age group of 21 to 30 years. The mean age of male and female SLE patients were 24.83 and 25.68 respectively. The average duration of SLE was 37 months (3.08 years).

In this study $15(13.6 \%)$ patients were children (aged below 16 years) which is lower than the earlier reports indicating 15$17 \%$ of all SLE patients are children worldwide. Out of 110 SLE patients included in the study, $60(54.55 \%)$ patients suffered from infection. In a study done by de Luis et al., which included 96 cases of SLE, infections were reported in $55 \%$ of patients. H-Al-Rayes et al., in their retrospective study of 199 SLE patients in Saudi Arabia recorded infections in $58.79 \%$ of patients and the present study is comparable with both the above studies.

A total of 74 infections were observed in 60 patients in this study, out of which 51 patients experienced one infectious episode, 8 had two episodes of infection and one patient had 3 episodes of infection. In 4 patients with single episode of infection, two sites were involved. The most common sites of infection were the urinary tract and the respiratory tract which contributed to $54.05 \%$ and $16.22 \%$ of all the infections respectively. This preponderance of urinary and respiratory tract has also been observed in other studies conducted by Ginzler E et al., Staples P J et al., and de Luis et al. 
Other sites involved in the present study were blood $(12.16 \%)$, skin and soft tissue $(10.81 \%)$, ear $(2.7 \%)$, oral cavity $(2.7 \%)$ and peritoneum (1.35\%). de Luis et al., reported skin and soft tissue and blood as the third and fourth common sites of infection. In this study, bacterial infections $93.24 \%$ (69 out of 74) were common than fungal infections. This is in agreement with earlier reports of upto $80 \%$ incidence of bacterial infections in SLE patients from India, Malaysia, Singapore, Spain and U.S.A. Most frequently isolated uropathogen was E.coli $(50 \%)$, a result which is similar to that described by $\mathrm{C}$ Hidalgo- Tenorio et al., in their study in Spain. Klebsiella pneumoniae was the frequently isolated organism from respiratory tract.

In this study, $9(12.16 \%)$ patients had one episode of bacteremia and the leading cause of Gram positive bacteremia was Staphylococcus aureus and Gram negative bacteremia was Klebsiella pneumoniae and Pseudomonas aeruginosa. Chen et al., in their study documented bacteremia in $17 \%$ of SLE patients. The result of the present study is lower than the above study. Salmonella bacteremia was present in one patient. An increased association of Salmanellosis in SLE patients has already been reported by Reyes et al.

Table.1 Frequency of Patients with and Without Infection

$$
n=110
$$

\begin{tabular}{|c|c|c|}
\hline \multicolumn{1}{|c|}{ Patients distribution $\downarrow \downarrow \downarrow$} & No. & Percentage \\
\hline No. of Patients with Infection & 60 & $54.55 \%$ \\
\hline No. of Patients without Infection & 50 & $45.45 \%$ \\
\hline \hline Total & $\mathbf{1 1 0}$ & $\mathbf{1 0 0 . 0 0 \%}$ \\
\hline
\end{tabular}

Table.2 Distribution of Isolated organisms

Bacterial Isolates

\begin{tabular}{|l|c|}
\hline \multicolumn{1}{|c|}{ Bacteria Isolated } & Number \\
\hline Escherichia coli & 20 \\
\hline Pseudomonas aeruginosa & 14 \\
\hline Klebsiellapneumoniae & 12 \\
\hline Staphylococcus aureus & 10 \\
\hline Staphylococcus epidermidis & 3 \\
\hline Acinetobacterbaumannii & 2 \\
\hline Enterococcus faecalis & 2 \\
\hline Proteus mirabilis & 2 \\
\hline Citrobacterfreundii & 1 \\
\hline Klebsiellaoxytoca & 1 \\
\hline Salmonella typhi & 1 \\
\hline \hline Total & $\mathbf{6 8}$ \\
\hline
\end{tabular}




\section{Fungal Isolates}

\begin{tabular}{|l|c|}
\hline \multicolumn{1}{|c|}{ Fungi Isolated } & Number \\
\hline Candida albicans & 4 \\
\hline Candida tropicalis & 1 \\
\hline Aspergillusflavus & 1 \\
\hline \hline Total & $\mathbf{6}$ \\
\hline
\end{tabular}

Table.3 Distribution of Organisms Isolated from Respiratory Tract

$$
\mathrm{n}=12
$$

\begin{tabular}{|c|c|c|}
\hline Organism Isolated & Number & Percentage \\
\hline \multicolumn{3}{|c|}{ Gram Negative Bacteria } \\
\hline Klebsiellapneumoniae & 8 & $66.67 \%$ \\
\hline Pseudomonas aeruginosa & 2 & $16.67 \%$ \\
\hline \multicolumn{3}{|c|}{ Gram Positive Bacteria } \\
\hline Staphylococcus aureus & 1 & $8.33 \%$ \\
\hline Staphylococcus epidermidis & 1 & $8.33 \%$ \\
\hline Total & 12 & \\
\hline
\end{tabular}

Table.4 Distribution of Organisms Isolated from Blood

$$
\mathrm{n}=9
$$

\begin{tabular}{|c|c|c|}
\hline Organism Isolated & Number & Percentage \\
\hline \multicolumn{3}{|c|}{ Gram Negative Bacteria } \\
\hline Klebsiellapneumoniae & 2 & $22.22 \%$ \\
\hline Pseudomonas aeruginosa & 2 & $22.22 \%$ \\
\hline Salmonella typhi & 1 & $11.11 \%$ \\
\hline Acinetobacterbaumannii & 1 & $11.11 \%$ \\
\hline \multicolumn{3}{|c|}{ Gram Positive Bacteria } \\
\hline Staphylococcus aureus & 2 & $22.22 \%$ \\
\hline Staphylococcus epidermidis & 1 & $11.11 \%$ \\
\hline Total & 9 & \\
\hline
\end{tabular}


Table.5 Distribution of Organisms Isolated from Skin and Soft Tissue $\mathrm{n}=8$

\begin{tabular}{|l|c|c|}
\hline \multicolumn{1}{|c|}{ Organism Isolated } & No. of & Percentage \\
\hline Pseudomonas aeruginosa & 4 & $50.00 \%$ \\
\hline Staphylococcus aureus & 3 & $37.50 \%$ \\
\hline Candida albicans & 1 & $12.50 \%$ \\
\hline \hline Total & 8 & \\
\hline
\end{tabular}

Fig.1 Distribution of Infections in Various Sites

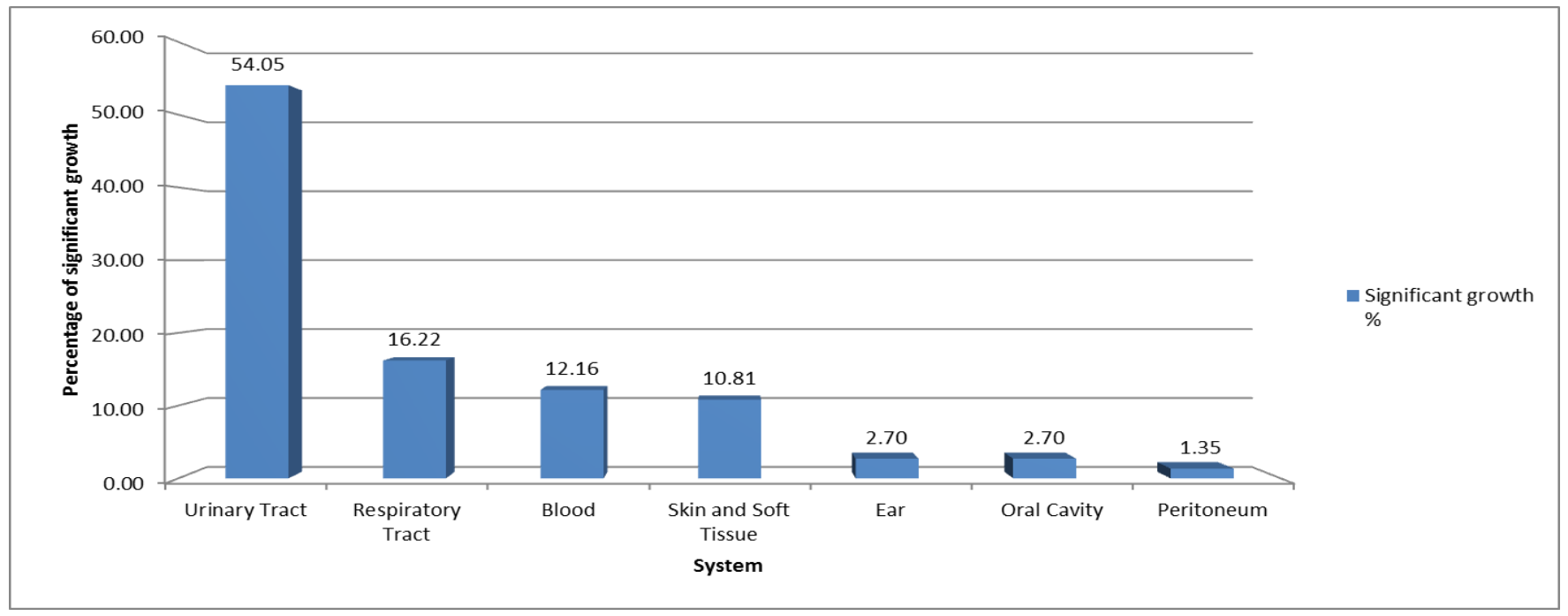

Fig.2 Distribution of organisms isolated from urinary tract

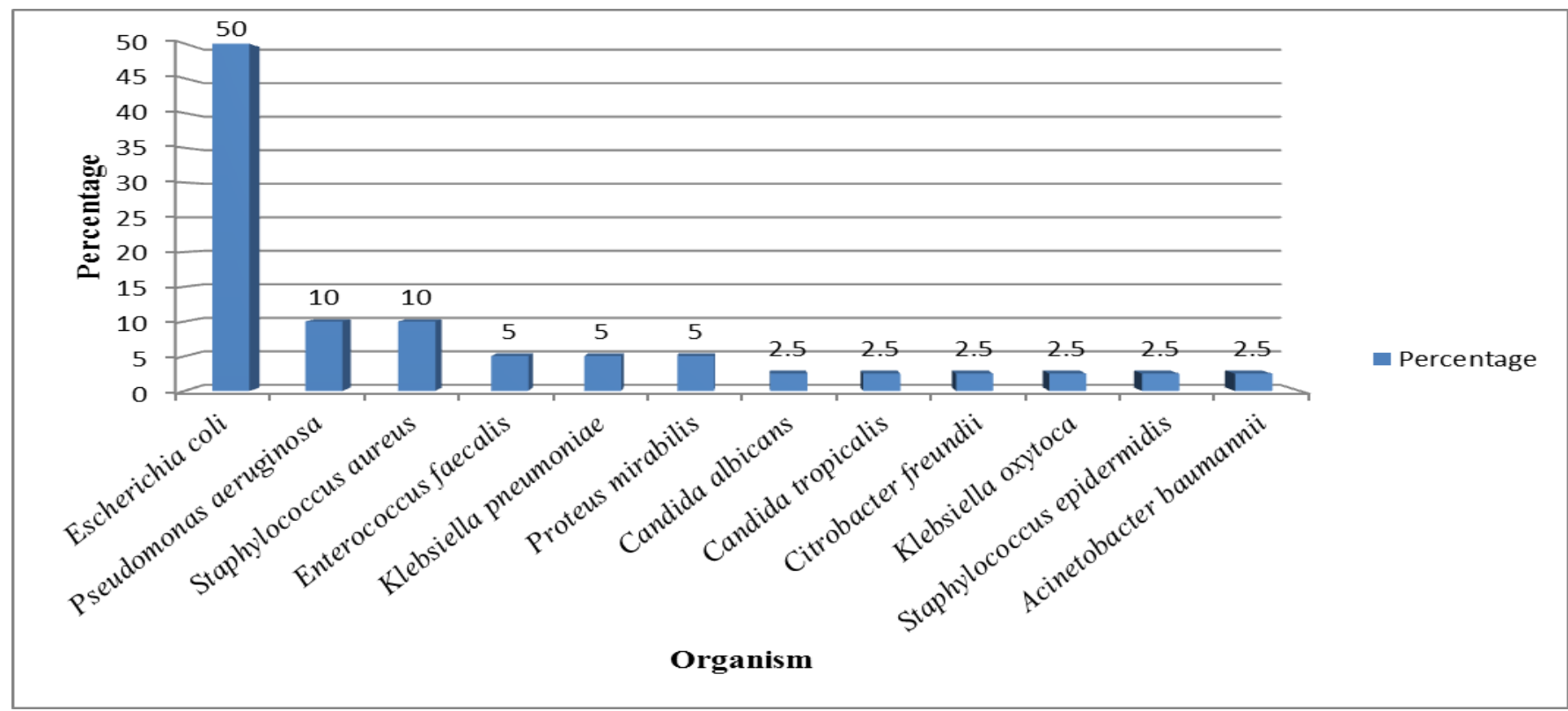


Pseudomonas aeruginosa was the common isolate from skin and soft tissue followed by Staphylococcus aureus and Candida albicans. The other less frequently involved sites were ear, oral cavity and peritoneum. In the present study, 8 patients had history of tuberculosis. In a study done in South Indian SLE patients by Kosaraju et al., history of tuberculosis had been reported in 6 patients.

Fungus was isolated from 6 patients and accounted for $8.1 \%$ of infections. Candida was the most common fungus isolated. Candida albicans was isolated from 4 patients and Candida tropicalis from one patient. This is in agreement with Ginzler et al., who observed that Candida infection is the common fungal infection in patients with SLE most often presenting with oral thrush. In astudy done by H-Al-Rayes et al., Candida albicans is the most common fungus associated with infections in SLE patients. Aspergillus flavus was isolated from a case of SLE with ear infection. Ruiz Irastorza et al., reported a case of Aspergillus infection in their study in 83 patients with SLE.

Out of 110 SLE patients, 3 patients died during the study period. All the three patients were female and were on immunosuppressive therapy. Pneumonia was the cause of death in two patients and sepsis in one patient. Thus in all three cases, infection was the cause of death. This finding is supported by studies done by Barnatsky et al., and Doria et al., who have also reported infection as the major cause of death in SLE patients.

In conclusion, from this study it is evident that SLE patients are at high risk for infections. The most frequently involved sites of infection and the bacterial and fungal profile of these infections are similar to those reported in patients without SLE. It was found that bacterial infections were common than fungal infections and urinary tract was the most common site of infection followed by respiratory tract. The common bacteria and fungus isolated were E.coli and Candida respectively. Therefore it is essential to evaluate all fever in SLE patients as the symptoms of SLE may mimic infection in several ways. Also the cautious and judicious use of steroids and other immunosuppressants is vital in controlling infections in SLE patients.

\section{References}

Malaviya A.N. 1988. Systemic lupus erythematosus in northern India: A review of 329 cases. J. Assoc. Physicians India, 36: 476-480.

Jacobsen, S., Petersen, J., Villman, S., et al. 1999. Mortality and causes of death of 513 Danish patients with SLE. Scandinavian J. Rheumatol.,.Vol.2 pg. 75-80.

RenuSaigal, Amit Kansal, Manoop Mittal, Yadvinder Singh, Hari Ram Maharia, Manish Juneja. 2011. Clinical profile of systemic lupus erythematosus patients at a tertiary care centre in Western India. JIACM, 13(1): 27-32.

Faller, G., Thomson, P.D., Kala, U.K., Hahn, D. 2005. Demographics and presenting clinical features of childhood systemic lupus erythematosus. S. Afr. Med. J., 95: 424-427.

de Luis, A., Pigrau, C., Pahissa, A. et al. 1990. Infections in 96 cases of systemic lupus erythematosus. Med. Clin. (Barc), 94: 607-610.

Al-Rayes, H., R. Al-Swailem, M. Arfin, S. Sobki, S. Rizvi, M Tariq. 2007. Systemic lupus erythematosus and infections: a retrospective study in Saudis. Lupus, 16: 755-763.

Ginzler, E., Diamond, H., Kaplan, D., et al. Computer analysis of factors 
influencing frequency of infection in systemic lupus erythematosus. Arthritis Rheum., 21: 37-44.

Staples, P.J., Gerding, D.N., Decker, J.L., et al. 1974. Incidence of infection in systemic lupus erythematosus. Arthritis Rheum., 17: 1-10.

Shyam, C., Malaviya, A.N. 1996. Infectionrelated morbidity in systemic lupus erythematosus: a clinicoepidemiological study from northern India. Rheumatol. Int., 16: 1-3.

Paton, N.I., Cheong, I.K., Kong, N.C. et al. 1996. Risk factors for infection in Malaysian patients with systemic lupus erythematosus. Q. J. Med., 9: 531- 38 .

Oh, H.M., Chng, H.H., Boey, M.L. et al. 1993. Infections in systemic lupus erythematosus. Singapore Med. J., 34: 406-408.

Noel, V., Lortholary, O., Casassus, P. et al. 2001. Risk factors and prognostic influence of infection in a single cohort of 87 adults with systemic lupus erythermatosus. Ann. Rheum. Dis., 60: 1141- 44.

Yi-Chan, Tsai, 1., Chih-Lung. Hou, TsungChieh Yao, Li-Chen Chen, Tang-Her Jaing, Jing-Long Huang. 2007. Risk Factors and Bacterial Profiles of Urinary Tract Infections in Patients with Systemic Lupus Erythematosus. Asian Pacific J. Allergy and Immunol., 25: 155-161.

Chen, M.J., H.M. Tseng. et al. 2008. Long term outcome and short term survival of patients with Systemic Lupus Erythematosus after bacteremia episodes: 6 year follow-up. Rheumatol., 47(9):1352-57.

Reyes, C.M., Navarra, S.V. 2005. Infections among Filipino patients with systemic lupus erythematosus. Phil. J. Int. Med., 43: 123-127.

Kosaraju, K., S. Shenoy, U. Suchithra. 2010. A cross-sectional hospital-based study of autoantibody profile and clinical manifestations of systemic lupus erythematosus in south Indian patients. IJMM, 28(3): 245-7.

Ginzler, E., Diamond, H., Kaplan, D. et al. 1978. Computer analysis of factors influencing frequency of infection in systemic lupus erythematosus. Arthritis Rheum., 21: 37-44.

Guillermo Ruiz-Irastorza, Nerea Olivares, Ioana Ruiz-Arruza, Agustin MartinezBerriotxoa, Maria-Victoria Egurbide, Ciriaco Aguirre. 2009. Predictors of major infections in systemic lupus erythematosus. Arthritis Res. Therapy, 11: R109.

Barnatsky, S,. Boivin, J.F., Joseph, L. et al. 2006. Mortality in systemic lupus erythematosus. Arthritis Rheum., 54: 2550-57.

Doria, A., Iaccarino, L., Ghirardello, A. et al. 2006. Long-term prognosis and causes of death in systemic lupus erythematosus. Am. J. Med., 119: 700706.

\section{How to cite this article:}

Shiney John, V., S. Vasanthi and Rathnapriya, N. 2016. A Study on Bacterial and Fungal Profile of Infections in Patients with SLE. Int.J.Curr.Microbiol.App.Sci. 5(6): 431-438. doi: http://dx.doi.org/10.20546/ijcmas.2016.506.050 